\title{
Differential Palmitoylation Directs the AMPA Receptor-Binding Protein ABP to Spines or to Intracellular Clusters
}

\author{
Sunita DeSouza, Jie Fu, Bradley A. States, and Edward B. Ziff \\ Howard Hughes Medical Institute, Department of Biochemistry, New York University School of Medicine, New York, \\ New York 10016
}

\begin{abstract}
Long-term changes in excitatory synapse strength are thought to reflect changes in synaptic abundance of AMPA receptors mediated by receptor trafficking. AMPA receptor-binding protein (ABP) and glutamate receptor-interacting protein (GRIP) are two similar PDZ (postsynaptic density 95/Discs large/zona occludens 1) proteins that interact with glutamate receptors 2 and 3 (GluR2 and GluR3) subunits. Both proteins have proposed roles during long-term potentiation and long-term depression in the delivery and anchorage of AMPA receptors at synapses. Here we report a variant of ABP-L (seven PDZ form of ABP) called $\mathrm{PABP}-\mathrm{L}$ that is palmitoylated at a cysteine residue at position 11 within a novel 18 amino acid N-terminal leader sequence encoded through differential splicing. In cultured hippocampal neurons, nonpalmitoylated ABP-L localizes with internal GluR2 pools expressed from a Sindbis virus vector,
\end{abstract}

whereas $\mathrm{PABP}-\mathrm{L}$ is membrane targeted and associates with surface-localized GluR2 receptors at the plasma membrane in spines. Mutation of Cys-11 to alanine blocks the palmitoylation of $\mathrm{pABP}-\mathrm{L}$ and targets the protein to intracellular clusters, confirming that targeting the protein to spines is dependent on palmitoylation. Non-palmitoylated GRIP is primarily intracellular, but a chimera with the pABP-L N-terminal palmitoylation sequence linked to the body of the GRIP protein is targeted to spines. We suggest that PABP-L and ABP-L provide, respectively, synaptic and intracellular sites for the anchorage of AMPA receptors during receptor trafficking to and from the synapse.

Key words: palmitoylation; glutamate receptor; AMPA receptor; AMPA receptor-binding protein; glutamate receptor interacting protein; alternative splicing
The AMPA subtype of glutamate receptors (GluRs) is a heterotetrameric complex, assembled from up to four different subunits (GluR1-GluR4), that provides the major source of fast, excitatory synaptic transmission (Hollmann and Heinemann, 1994). It is now established that changes in synaptic AMPA receptor abundance influence synaptic strength during long-term potentiation (LTP) and long-term depression (LTD) (Carroll et al., 1999; Luscher et al., 1999; Hayashi et al., 2000; Lu et al., 2001). Such regulation requires an intracellular system for controlling receptor trafficking and targeting. AMPA receptors and other glutamate receptors bind cytosolic adapter proteins that contain PDZ [postsynaptic density 95 (PSD-95)/Discs large/zona occludens 1] domains (Kornau et al., 1995; Niethammer et al., 1996; Brakeman et al., 1997; Dong et al., 1997; Leonard et al., 1998; Srivastava et al., 1998; Xia et al., 1999). Two similar proteins, AMPA receptor-binding protein (ABP) and glutamate receptor-interacting protein (GRIP), bind to the $C$ terminus of the GluR2 and GluR3 subunits of AMPA receptors (Dong et al., 1997; Srivastava et al., 1998). GRIP and ABP-L (long) have seven PDZ domains, whereas ABP-S (short) has six PDZ domains. $\mathrm{ABP}$ and GRIP are reported to stabilize receptors at the postsynaptic membrane (Dong et al., 1999a; Osten et al., 2000). During

Received Aug. 6, 2001; revised Jan. 30, 2002; accepted Feb. 5, 2002.

B.A.S. was supported by National Institutes of Health Grant AG13620 (E.B.Z.). S.D. and J. F. are Associates and E.B.Z. is an Investigator of the Howard Hughes Medical Institute. We thank J. Hanley, I. Greger, and C. Misra for critical reading of this manuscript, D. Bredt for helpful discussions, and T. Serra for help in preparation of this manuscript.

Correspondence should be addressed to Edward B. Ziff, Howard Hughes Medical Institute, Department of Biochemistry, New York University School of Medicine, New York, NY 10016. E-mail: edward.ziff@med.nyu.edu.

Copyright (ㄷ) 2002 Society for Neuroscience 0270-6474/02/223493-11\$15.00/0 cerebellar LTD, GluR2 subunits at parallel fiber-Purkinje cell synapses are phosphorylated at the PDZ binding site, which blocks ABP/GRIP binding, leading to receptor internalization (Chung et al., 2000; Matsuda et al., 2000; Xia et al., 2001). In the hippocampus, internalized receptors may bind to intracellular pools of ABP/GRIP, which are proposed to anchor the receptors at intracellular membranes, preventing synaptic reinsertion (Daw et al., 2000). Indeed, a large proportion of GluR2 and ABP/GRIP is found at intracellular dendritic locations (Burette et al., 2001) (I. Greger, L. Khatri, and E. B. Ziff, unpublished observation). This suggests that anchoring proteins stabilize receptors at both the synapse and intracellular, subsynaptic locations.

Many cytosolic proteins that function at the plasma membrane associate with the membrane via lipophilic substituents (Hancock et al., 1989; Wedegaertner et al., 1993; Alland et al., 1994). Thioesterification of cysteine residues with the fatty acid palmitate tethers proteins to the inner leaflet of the plasma membrane and targets proteins to lipid rafts and caveolae (for review, see Mumby, 1997; Resh, 1999). Membrane localization and clustering of ion channels by the synaptic PDZ-containing protein PSD-95 depends on palmitoylation of two cysteine residues in the PSD-95 $\mathrm{N}$ terminus (Topinka and Bredt, 1998; El-Husseini et al., 2000b).

Here we report the cloning and characterization of pABP-L, an $\mathrm{N}$-terminal splice variant of ABP-L that contains a unique 18 amino acid (aa) N-terminal sequence that is palmitoylated on a cysteine residue at position 11. In hippocampal neurons, pABP-L localizes in spines, whereas ABP-L and GRIP, which are not palmitoylated, localize mainly in dendritic shafts rather than spines. ABP-L colocalizes predominantly with internal GluR2 stores, whereas pABP-L is associated mainly with receptors at the plasma membrane. This suggests that differential palmitoylation 
enables ABP to play a dual role in the trafficking of receptors, serving as an anchor that stabilizes receptors at the synapse and at subsynaptic, intracellular locations.

\section{MATERIALS AND METHODS}

Library screening and expression vectors. An oligo-dT + random-primed $\lambda$ gt10 adult rat brain cDNA library (Clontech, Palo Alto, CA) was screened using two different probes corresponding to either PDZ domains 1-3 or PDZ domains 4-6 of ABP. cDNA probes were labeled with $100 \mu \mathrm{Ci}$ of $\left[{ }^{32} \mathrm{P}\right] \mathrm{dCTP}(3000 \mathrm{Ci} / \mathrm{mmol}$; NEN, Boston, MA) using the Prime It Kit (Stratagene, La Jolla, CA). Of the $>1.0$ million clones screened, several independent partial clones of ABP were isolated that contained a seventh PDZ domain and two different $\mathrm{N}$ termini. The full-length ABP-L and pABP-L were Flag-tagged on the $\mathrm{C}$ terminus and cloned into the EcoRI/Not I site of pcDNA3 (Invitrogen, Carlsbad, CA). PSD-95 in the GW1 vector was a generous gift from M. Sheng (Massachusetts Institute of Technology, Cambridge, MA). For construction of green fluorescent protein (GFP)-tagged vectors, GRIP1 was cloned into the HinDIII site of the pEGFP-N vector, whereas ABP-L and pABP-L were cloned into the EcoRI/KpnI site of pEGFP-N3 vector (Clontech). Single and double amino acid changes in the pABP-L $N$ terminus were made by PCR mutagenesis using wild-type (WT) pABP-L-GFP plasmid as a template. All mutations were confirmed by DNA sequencing. For recloning into pSinRep5 vector (Invitrogen), the Flag-tagged pABP-L, C11A, and W4A cDNAs were excised from pcDNA3 in the following way: the $5^{\prime}$ end of the insert was initially digested with EcoRI, bluntended, and ligated with $X b a I$ linkers (New England Biolabs, Beverly, MA). Subsequent digestion with $X b a$ I cleaved the $3^{\prime}$ end of the insert, releasing the $3.2 \mathrm{~kb}$ pABP-L fragment that was cloned into the $X b a \mathrm{I}$ site of pSinRep5. ABP-L and pABP-L tagged with GFP inserts were generated by PCR and cloned into the $X b a I$ site of pSinRep5. An additional glycine residue was inserted after the methionine start codon for better expression and had no effect on the overall pattern of expression (data not shown). GRIP tagged with the Myc epitope on the $\mathrm{C}$ terminus was cloned into pSinRep by digestion with SalI and subsequent ligation into the $X b a$ I site as described above. To replace GRIP1 $\mathrm{N}$ terminus with the 52 aa pABP-L N terminus, we used two-step PCR and digestion to generate a chimera containing the $\mathrm{N}$ terminus of $\mathrm{pABP}-\mathrm{L}$ fused to the GRIP1 protein to the middle of linker 1 with $X b a I$ and BamHI (contained in the linker 1 region of native GRIP) sticky ends. The rest of GRIP was excised from pSinRep-GRIP-Myc with Bam HI and SphI, and both fragments were ligated into the $X b a \mathrm{I} / S p h \mathrm{I}$ sites of pSinRep. This triple ligation resulted in a full-length pABP-L(N)/GRIP1-Myc fusion protein. The correct orientation of inserts and integrity of all expression plasmids generated above was confirmed by digestion and sequencing.

Transfection of human embryonic kidney $293 T$ cells and coimmunoprecipitation in vitro. Human embryonic kidney 293T (HEK 293T) cells were cotransfected with $5 \mu \mathrm{g}$ of GluR2 cDNA and $5 \mu \mathrm{g}$ of the appropriate Flag-tagged ABP plasmids using the calcium phosphate method. Forty-eight hours after transfection, cells were washed once with $1 \times$ PBS and scraped in $1 \mathrm{ml}$ of cold PBS. Cells were solubilized in $1 \%$ Triton $\mathrm{X}-100$ lysis buffer (25 mM HEPES, pH7.5, $150 \mathrm{~mm} \mathrm{NaCl,} 1 \%$ Triton $\mathrm{X}-100,2 \mathrm{~mm}$ EDTA, and $2 \mathrm{~mm}$ EGTA) for $1 \mathrm{hr}$ on ice. Insoluble material was pelleted out, and $1 \mu \mathrm{g}$ of M2 Flag monoclonal antibody (Ab) (Sigma, St. Louis, MO) was added to the supernatant to immunoprecipitate (IP) ABPs for $1 \mathrm{hr}$ at $4^{\circ} \mathrm{C}$. Twenty microliters of Protein $\mathrm{G}$ beads (Santa Cruz Biotechnology, Santa Cruz, CA) was added for $30 \mathrm{~min}$ and washed three times in $1 \mathrm{ml}$ of Triton X-100 lysis buffer. The proteins from the IP were separated on $8 \%$ SDS-PAGE, transferred onto nitrocellulose, and probed with $0.5 \mu \mathrm{g} / \mathrm{ml} \mathrm{GluR2/3} \mathrm{C}$-terminal polyclonal antibody (Chemicon, Temecula, CA) in 5\% nonfat milk. Duplicate gels were loaded with $5 \%$ of the HEK 293 T lysates used for each IP and probed with the GluR2/3 antibody and then stripped and reprobed with an antibody directed against the linker 2 region of ABP (Link2 Ab) (Srivastava et al., $1998)$ to check for protein expression.

GFP expression in heterologous cells. HeLa cells and COS-7 cells were seeded on glass coverslips the day before transfection at $40 \%$ confluency. Cells were transiently transfected with $2 \mu \mathrm{g}$ of GRIP1-GFP, ABP-LGFP, or pABP-L-GFP plasmid using SuperFect Transfection Reagent (Qiagen, Valencia, CA) following the instructions of the manufacturer. At 18-24 hr after transfection, the coverslips were inverted over a microwell slide, and GFP fluorescence was observed in live cells using the Nikon (Tokyo, Japan) PCM 2000 confocal microscope.

RNA extraction and reverse transcription-PCR assay. Total RNA was extracted from adult male Sprague Dawley rat tissue using the guanidinium thiocyanate-phenol-chloroform method (Chomczynski and Sacchi, 1987). Briefly, tissue samples were dounced in $4.0 \mathrm{ml}$ of solution $\mathrm{D}$ (4 M guanidium thiocyanate, $25 \mathrm{~mm}$ sodium citrate, $0.5 \%$ sarcosyl, and $0.1 \mathrm{~m} 2$-mercaptoethanol). Sodium acetate at $2 \mathrm{~m}(0.4 \mathrm{ml}), \mathrm{pH} 4.0,4 \mathrm{ml}$ of phenol, $\mathrm{pH} 4.3$, and $0.8 \mathrm{ml}$ of chloroform/isoamyl alcohol mixture $(49: 1)$ was added to the tissue homogenate, vortexed thoroughly, and chilled on ice for $15 \mathrm{~min}$ before centrifugation at $10,000 \times g$ for $20 \mathrm{~min}$ at $4^{\circ} \mathrm{C}$. The RNA in the aqueous phase was precipitated in 1 vol of isopropanol for $2 \mathrm{hr}$ at $-20^{\circ} \mathrm{C}$. Samples were centrifuged at $10,000 \times g$ for $20 \mathrm{~min}$ at $4^{\circ} \mathrm{C}$, and the pellet was resuspended in $0.3 \mathrm{ml}$ of solution $\mathrm{D}$ and reprecipitated with $1 \mathrm{vol}$ of isopropanol at $-20^{\circ} \mathrm{C}$ for $2 \mathrm{hr}$. The final RNA pellet was recovered by centrifugation at $15,000 \mathrm{rpm}$ in a microfuge for $15 \mathrm{~min}$ and resuspended in RNase-free water. For first-strand cDNA synthesis, $2 \mu \mathrm{g}$ of total RNA was diluted to a total volume of $10 \mu \mathrm{l}$ along with $0.5 \mu \mathrm{g}$ of oligo-dT (16-mer). The sample was heated to $70^{\circ} \mathrm{C}$ for 10 min and allowed to cool on ice for at least $5 \mathrm{~min}$. For the reverse transcription (RT) reaction, $10 \mu \mathrm{l}$ of enzyme mixture [4 $\mu \mathrm{l}$ of $5 \times \mathrm{RT}$ buffer, $2 \mu \mathrm{l}$ of $10 \mathrm{~mm}$ dNTPs, $2 \mu \mathrm{l}$ of $0.1 \mathrm{M} \mathrm{DTT}, 1 \mu \mathrm{l}$ of RNAsin (Promega, Madison, WI), and $1 \mu$ l of Superscript RT (Invitrogen)] was added, and the RT reaction was incubated at $47^{\circ} \mathrm{C}$ for $2.5 \mathrm{hr}$. Samples were heated to $95^{\circ} \mathrm{C}$ for $5 \mathrm{~min}$ to destroy enzymatic activity. Twenty percent of the RT reaction $(4 \mu \mathrm{l})$ was used directly as template for subsequent PCR. The following upstream primers were used for PCR: ABP-L (up), 5' -atgttggcggtgtcactcaagtggcgg-3'; pABP-L (up), 5'-atgcggggctggcgcaggaacctcgcg-3'; and GRIP1 (up), 5'-atgatagctgtctctttaaatgccgc-3'. The downstream primer for both ABP-L and pABP-L was 5'-gggttcatagttggcgaggagaagg-3', and, for GRIP1, it was $5^{\prime}$-gtaaagtcccatgttcagggaactcaggc- $3^{\prime} .\left[{ }^{32} \mathrm{P}\right] \mathrm{dATP}$ at $2.5 \mu \mathrm{Ci}(800 \mathrm{mCi} /$ $\mathrm{mmol}$ ) was included in each PCR reaction. Annealing temperature was $60^{\circ} \mathrm{C}$, and the PCR reaction was performed for 50 cycles. PCR products were separated on $5 \%$ nondenaturing acrylamide gels in $0.5 \times 50 \mathrm{~mm}$ Tris, pH 8.0, $45 \mathrm{~mm}$ Boric acid, and $1 \mathrm{~mm}$ EDTA, dried under vacuum, and exposed to x-ray film for $30 \mathrm{~min}$. NIH Image software was used to analyze the PCR products.

Metabolic labeling and analysis of palmitoylation. COS-7 cells were plated on $6 \mathrm{~cm}$ tissue culture dishes at $\sim 60-70 \%$ confluency the day before transfection. Five micrograms of the appropriate cDNA plasmid were transfected using SuperFect. At $48 \mathrm{hr}$ after transfection, the cells were metabolically labeled with $\left[{ }^{3} \mathrm{H}\right]$ palmitic acid as described previously (Topinka and Bredt, 1998). Briefly, cells were preincubated for $30 \mathrm{~min}$ in serum-free DMEM with $3 \mu \mathrm{g} / \mathrm{ml}$ cerulenin (Sigma) and $10 \mathrm{mg} / \mathrm{ml}$ fatty acid-free BSA. $\left[{ }^{3} \mathrm{H}\right]$ palmitic acid at $1 \mathrm{mCi} / \mathrm{ml}(50 \mathrm{Ci} / \mathrm{mmol})$ was added to the cells and incubated for $4 \mathrm{hr}$ at $37^{\circ} \mathrm{C}$. Cells were rinsed once with PBS and scraped in $1 \mathrm{ml}$ of cold PBS, centrifuged, and resuspended in $1 \mathrm{ml}$ of cold radioimmunoprecipitation analysis (RIPA) buffer (1\% NP-40, 0.5\% sodium deoxycholate, and $0.1 \%$ SDS in PBS). Cell extracts were rocked at $4^{\circ} \mathrm{C}$ for $1 \mathrm{hr}$, and insoluble material was pelleted out by centrifugation. The supernatant was used in IPs as described above, and the antibodies used were as follows: $1 \mu \mathrm{g}$ of anti-human PSD-95 antibody (Upstate Biotechnology, Lake Placid, NY), $1 \mu \mathrm{g}$ of c-Myc antibody (Santa Cruz Biotechnology), and $1 \mu \mathrm{g}$ of Link2 antibody (Srivastava et al., 1998). IPs were washed three times with $1 \mathrm{ml}$ of RIPA buffer and boiled in SDS-PAGE sample buffer with 1 mm DTT instead of 2-mercaptoethanol before separation on an $8 \%$ SDS gel. For fluorography, gels were incubated in fixative (40\% methanol and 10\% acetic acid) for $20 \mathrm{~min}$ and in Amplify (Amersham Biosciences, Piscataway, NJ) for $30 \mathrm{~min}$, dried under heat and vacuum, and exposed to Hyperfilm MP (Amersham Biosciences). For Western blots, $1 / 10$ of each sample was blotted onto nitrocellulose and probed with the appropriate antibody to check protein expression and efficiency of the IP. For hydroxylamine treatment, duplicate gels were incubated with either $1 \mathrm{M}$ hydroxylamine $\left(\mathrm{NH}_{2} \mathrm{OH}\right), \mathrm{pH} 7.0$ or $1 \mathrm{M}$ Tris- $\mathrm{HCl}, \mathrm{pH} 7.0$, for $18-24 \mathrm{hr}$ at $25^{\circ} \mathrm{C}$ before fluorography. Hippocampal neurons ( 3 weeks in culture) in $10 \mathrm{~cm}$ dishes were infected with $250 \mu \mathrm{l}$ of the appropriate virus. Twenty-hour hours after infection, cells were metabolically labeled in Neurobasal medium (Invitrogen) supplemented with BSA and cerulenin for $4 \mathrm{hr}$. Neurons were harvested and processed for Western blot analysis and fluorography as described above.

Sindbis virus infection of neuronal cultures and immunocytochemistry. ABP-L-GFP, pABP-L-GFP, MycGluR2, pABP-L-Flag (WT, C11A, and W4A), GRIP1-Myc, and pABP-L(N)/GRIP1-Myc pseudovirons were generated as described in the Sindbis Expression System manual (Invitrogen). Typically, $20 \mu$ l of viral stock was used to infect cultured hippocampal neurons $(21 \mathrm{~d}$ in culture) for $1 \mathrm{hr}$ (for details, see Osten et 


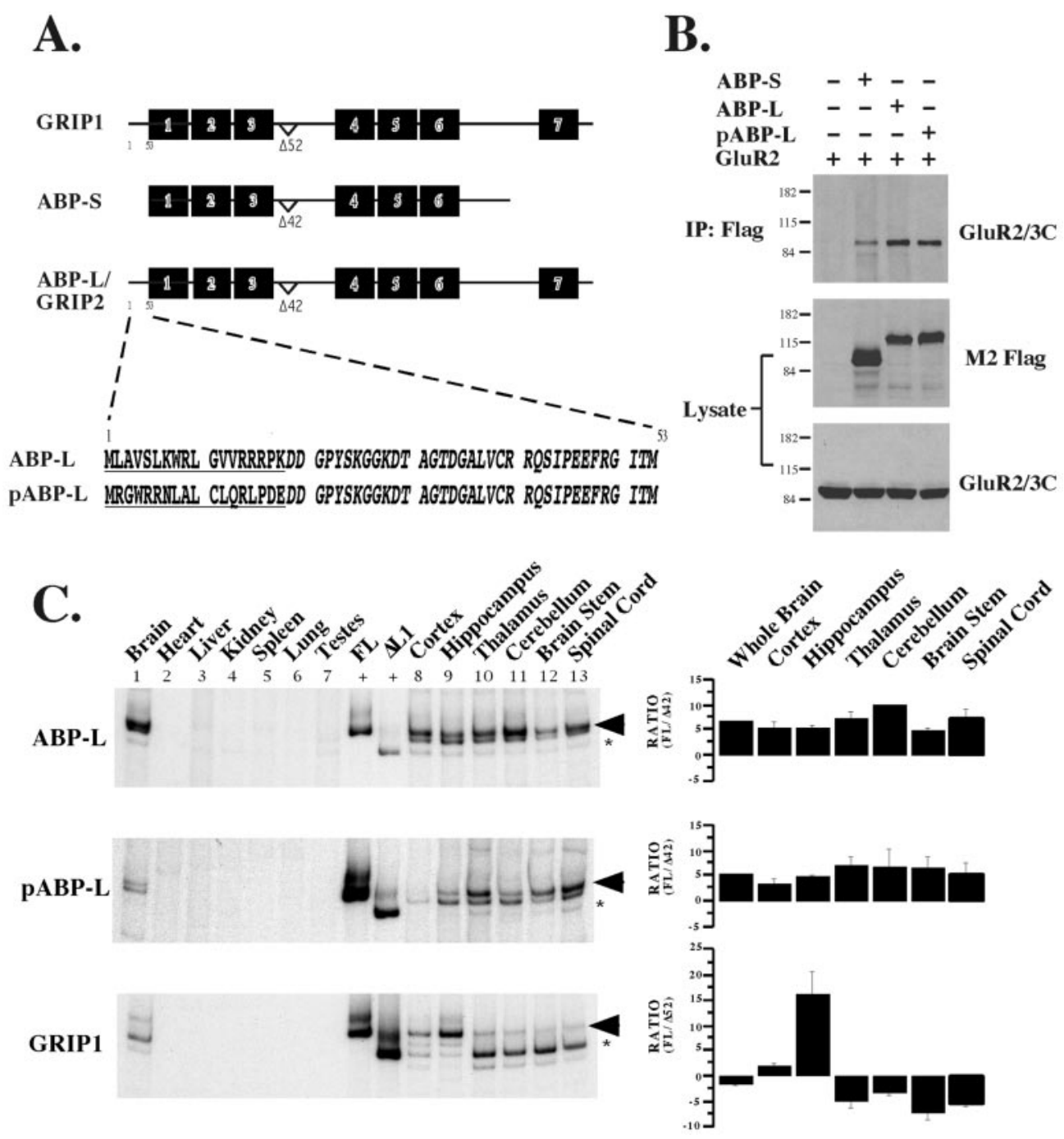

Figure 1. Schematic and mRNA expression patterns of different splice variants of GRIP and ABP. $A$, A $\lambda$ gt10 adult rat brain cDNA library (Clontech) was screened using two different probes corresponding to either PDZ domains $1-3$ or PDZ domains $4-6$ of ABP. Several different partial clones were identified, including some that had a seventh PDZ domain (ABP-L). There is a variable exon in the linker 1 region that splices out 52 aa $(\Delta 52)$ in GRIP with a corresponding deletion of 42 aa $(\Delta 42)$ in ABP. In addition, two different ABP $\mathrm{N}$-terminal splice variants (ABP-L and pABP-L) were identified that had 52 amino acids upstream of the first PDZ domain. The ABP-L and pABP-L splice variants differ from each other only in the first 18 aa (underlined). $B$, cDNAs encoding different ABPs were Flagtagged and cotransfected with the GluR2 cDNA in HEK 293T cells. Fortyeight hours after transfection, cell protein extracts were prepared in $1 \%$ Triton $\mathrm{X}-100,150 \mathrm{~mm} \mathrm{NaCl}$, and $20 \mathrm{~mm}$ HEPES buffer, $\mathrm{pH}$ 7.4, with protease inhibitors. Extracts were immunoprecipitated with $1 \mu \mathrm{g}$ of mouse monoclonal M2 Flag antibody (Sigma), run on an $8 \%$ SDS gel, transferred onto nitrocellulose membranes, and detected using a polyclonal antibody against the $\mathrm{C}$ terminus of the GluR2/3 receptor (Chemicon). HEK 293 T lysates were also immunoblotted against Flag and GluR2 to check protein expression. $C$, RT-PCR was performed using $2 \mu \mathrm{g}$ of total RNA isolated from adult rat tissues with $\left[{ }^{32} \mathrm{P}\right] \mathrm{dATP}$ included in the PCR reaction. PCR products were separated on $5 \%$ nondenaturing polyacrylamide gels, dried under vacuum, and exposed to $\mathrm{x}$-ray film for $30 \mathrm{~min}$. The message for all three proteins is present only in brain and neural tissue. ABP-L and pABP-L express mainly the full-length version in all brain regions (top two panels, lanes 8-13), whereas GRIP1 expresses mainly the linker $1(\Delta L 1)$ splice isoform (bottom panel, lanes 10-13) with the exception of cortex and hippocampus (lanes 8,9$)$ in which the full-length form predominates. Corresponding bar graphs on the right show fold increase of full-length $(F L)$ protein over deletion mutant $(\Delta 42$ or $\Delta 52)$ and averages data from three separate experiments.

al., 2000). For double infections with MycGluR2 and ABP-L-GFP or pABP-L-GFP virus, live neurons were incubated with $4 \mu \mathrm{g} / \mathrm{ml} \mathrm{Myc}$ monoclonal antibody (9E10; Santa Cruz Biotechnology) for 15 min at $37^{\circ} \mathrm{C}$. Cells were rinsed twice in $1 \times \mathrm{PBS}$, fixed in $4 \%$ paraformaldehyde, and permeabilized with $0.2 \%$ Triton X-100. Neurons were then incubated with $0.25 \mu \mathrm{g}$ of polyclonal Myc antibody (A14; Santa Cruz Biotechnology) in $2 \%$ nonfat milk for $45 \mathrm{~min}$ at $37^{\circ} \mathrm{C}$. After three washes, a 1:200 dilution of both rhodamine anti-mouse and Cy5 anti-rabbit secondary antibodies (Jackson ImmunoResearch, West Grove, PA) were added for $45 \mathrm{~min}$ before mounting on slides and visualization under the confocal microscope. For single infections with pABP-L-Flag, GRIP1Myc or pABP-L(N)/GRIP1-Myc, $25 \mu \mathrm{l}$ of virus was used to infect hippocampal neurons. After fixing and permeabilizing, either $1 \mu \mathrm{g} / \mathrm{ml}$ Myc monoclonal (Santa Cruz Biotechnology) or $0.4 \mu \mathrm{g} / \mathrm{ml}$ M2 Flag antibody (Sigma) was added for $1 \mathrm{hr}$. Cells were washed and incubated with $1 \mu \mathrm{g} / \mathrm{ml}$ Rhodamine Red-X anti-mouse secondary antibody (Molecular Probes, Eugene, OR) before visualization and analysis with the Nikon PCM 2000 confocal microscope. For single infections with Flagtagged pABP-L WT, C11A, and W4A virus, $0.4 \mu \mathrm{g} / \mathrm{ml} \mathrm{M} 2$ Flag antibody (Sigma) and $1 \mu \mathrm{g} / \mathrm{ml}$ GluR1 C-terminal antibody (Chemicon) were added to fixed and permeabilized neurons. Cells were washed and incubated with a 1:200 dilution of rhodamine anti-rabbit and fluoresceinconjugated anti-mouse secondary antibodies (Jackson ImmunoResearch, West Grove, PA) before visualization under the confocal microscope.

\section{RESULTS}

\section{Cloning of alternatively spliced $\mathrm{N}$-terminal forms of ABP/GRIP2}

ABP and GRIP were both identified by their ability to interact with the GluR2 C terminus in yeast two-hybrid assays (Dong et al., 1997; Srivastava et al., 1998). The initially reported form of ABP lacks a seventh PDZ domain and leader sequence at the $\mathrm{N}$ terminus of the protein, both found on GRIP (Fig. 1A). Subsequently, ABP-L, a splice variant clone of ABP containing a 52 aa leader and a seventh PDZ domain and thus similar to GRIP, was reported (Bruckner et al., 1999; Dong et al., 1999b). (GRIP by Dong et al., 1997 is also called GRIP-1, whereas ABP-L is also called GRIP-2.) The GRIP and ABP proteins have high sequence homology in the PDZ domains but little sequence similarity in the linker regions between the PDZ domains. Using a cDNA probe corresponding to the first three PDZ domains of $\mathrm{ABP}$, we probed a $\lambda \mathrm{gt10}$ adult rat brain cDNA library (Clontech) and isolated an alternatively spliced N-terminal clone of ABP-L, pABP-L (Fig. 1A). The ABP-L and pABP-L N termini differ 
from each other only in the first 18 amino acids. ABP clones were also obtained that contained the seventh PDZ domain (ABP-L) and that lacked 42 aa exonic sequence in the linker region between PDZ 3 and $4(\Delta 42)$, for which a corresponding 52 aa deletion was seen in GRIP-1 (Dong et al., 1999b). In the mouse genome, a majority of the exons coding for ABP are found within a $15 \mathrm{~kb}$ DNA region. By chromosome walking, the exon coding for the ABP-L N terminus was found to reside $\sim 18 \mathrm{~kb}$ upstream of this major ABP coding region (data not shown). The locus encoding the pABP-L $\mathrm{N}$ terminus was located even farther upstream, separated by an as yet indeterminate amount of intervening sequence.

To determine whether all three forms of ABP were capable of interacting with GluR2, plasmids expressing ABPs tagged at the C terminus with the Flag epitope were cotransfected with a plasmid expressing the GluR2 cDNA in HEK 293 T cells. At $48 \mathrm{hr}$ after transfection, cells were lysed and solubilized with $1 \%$ Triton $\mathrm{X}-100$, and ABP was immunoprecipitated from cell extracts using monoclonal antibody to the Flag epitope. Figure $1 B$ shows that GluR2 can be coimmunoprecipitated by the Flag antibody only when ABP is present. The efficiency of the interaction of ABP with GluR2 is greater with the forms of ABP that contain the seventh PDZ domain and N-terminal leader sequence compared with the six PDZ form, which lacks the leader.

\section{Endogenous expression of ABP-L, pABP-L, and GRIP}

To characterize the expression of the ABP-L and pABP-L proteins, we attempted to generate peptide antibodies that were directed against the $\mathrm{N}$-terminal 18 aa that distinguish these two ABP species but were not successful. Instead, we used RT-PCR to determine expression patterns of mRNAs encoding ABP-L versus pABP-L in different rat tissues. Total RNA was extracted from tissues using the guanidinium thiocyanate-phenol-chloroform method (Chomczynski and Sacchi, 1987). RT-PCR was performed using oligo-dT to prime the RT reaction and primers unique to the different ABP-L and GRIP1 N termini to distinguish between these different proteins. In addition, we used a $3^{\prime}$ primer between PDZ3 and PDZ4 (linker 1) that binds downstream of the 42 aa alternatively spliced region to determine which linker 1 splice isoform is expressed. [ $\left.{ }^{32} \mathrm{P}\right] \mathrm{dATP}$ was included in the PCR reaction to radiolabel the PCR products. Also included are positive controls in which cDNAs of both the fulllength and the linker 1 splice isoform were used as templates (Fig. $1 C$, between lanes 7 and 8 ). Figure $1 C$ shows that GRIP1, ABP-L, and $\mathrm{pABP}-\mathrm{L}$ are expressed only in brain and not in any of the other tissues tested, including heart, liver, kidney, spleen, lung, or testes. Although a GRIP-immunoreactive band was reported in testes (Wyszynski et al., 1998; Dong et al., 1999a), we were unable to detect GRIP1 message in testes. The proportion of message retaining the linker 1 variant exon (top band of the doublet) relative to the total for each brain region is indicated on the right. Both the full-length and the linker 1 splice isoforms of ABP-L and $\mathrm{pABP}-\mathrm{L}$ are expressed in all brain regions and spinal cord, with at least fivefold higher levels of mRNA encoding the fulllength protein compared with the shorter linker 1 isoform.

GRIP is also encoded in corresponding linker 1 variant forms. Both forms of GRIP were also expressed in all brain tissues tested, but the ratio of the two isoforms varied. In the cortex, there was approximately twice as much full-length protein compared with the $\Delta 52$ linker 1 isoform, and this ratio increased to greater than 10-fold in the hippocampus (Fig. 1C, lanes 8, 9, bottom panel and corresponding bar graph). In all other brain tissues, the linker 1 deletion protein ( $\Delta 52$ aa) is expressed predominantly. This result confirms a previous report of GRIP protein expression, in which the cortex and hippocampus expressed a "slow migrating" GRIP species, whereas cerebellum expressed mainly a "fast migrating" GRIP species, which now can be attributed to the full-length and $\Delta 52$ linker 1 GRIP protein species (Wyszynski et al., 1998). In addition, the differential expression of the two species of GRIP in the hippocampus versus the cerebellum indicates a possible tissue-specific function for the linker 1 splice variant.

\section{pABP-L localizes to the plasma membrane in heterologous cells}

It has been suggested that, through its ability to bind to GluR2, GRIP and ABP serve as adapter proteins involved in the targeting or anchoring of AMPA receptors at the synapse (Srivastava et al., 1998; Dong et al., 1999b). Recently, it has also been suggested that, rather than targeting receptors, these proteins are responsible for stabilizing AMPA receptors at the postsynaptic membrane (Osten et al., 2000). Both GRIP and ABP have been shown by electron microscopy and immunogold techniques to localize at the synaptic membrane and at intracellular structures in hippocampal neurons (Srivastava et al., 1998; Dong et al., 1999a; Burette et al., 2001). To determine whether the two N-terminal spliced versions of ABP-L have different subcellular localizations, we generated cDNAs expressing ABP tagged at the $\mathrm{C}$ terminus with GFP, which were expressed by transfection in HeLa and COS-7 cells. Cells were visualized $24 \mathrm{hr}$ after transfection with a confocal microscope. GRIP and ABP-L appeared to coalesce in the cytoplasm of the cell in large dense clusters. In contrast, pABP-L formed small puncta that associate exclusively with the plasma membrane of the cell (Fig. 2A). Because ABP-L and pABP-L are identical apart from their N-terminal leaders, this striking difference in subcellular localization may be attributed to the 18 aa difference at the $\mathrm{N}$ termini of these proteins.

\section{The $\mathbf{N}$ terminus of pABP-L is palmitoylated}

Many intracellular proteins that function at the plasma membrane are modified by myristoylation and palmitoylation (Resh, 1996). The synaptic PDZ-containing protein PSD-95 is dually palmitoylated, and this lipid modification on two cysteine residues at the $\mathrm{N}$ terminus is required for PSD-95 enhancement of postsynaptic clustering and activity of NMDA receptors (Topinka and Bredt, 1998; Craven et al., 1999; El-Husseini et al., 2000a; Tomita et al., 2001). The two cysteines of PSD-95 are surrounded by hydrophobic residues, which are also critical for palmitoylation and form a potential hydrophobic consensus palmitoylation sequence (El-Husseini et al., 2000b). The unique 18 aa $\mathrm{N}$ terminus of pABP-L that efficiently targets the protein to the cell membrane lacks the classical consensus sequence for $\mathrm{N}$-terminal myristoylation. However, it has a cysteine residue at position 11, which is flanked by hydrophobic residues in a sequence that is partially related to the proposed PSD-95 palmitoylation consensus sequence (El-Husseini et al., 2000b). Because this cysteine residue is absent from the ABP-L N terminus, we determined whether pABP-L is palmitoylated. COS cells expressing pABP-L, ABP-L, or PSD-95 as a control were metabolically labeled for $4 \mathrm{hr}$ with $\left[{ }^{3} \mathrm{H}\right]$ palmitic acid $(1 \mathrm{mCi} / \mathrm{ml}) 48 \mathrm{hr}$ after transfection. Cells were harvested and solubilized in RIPA buffer, and proteins were immunoprecipitated. $\left[{ }^{3} \mathrm{H}\right]$ Palmitate-labeled peptides, resolved by SDS-PAGE, were detected by fluorography. pABP-L was robustly palmitoylated in COS cells, as was PSD-95, 
A.
GRIP1

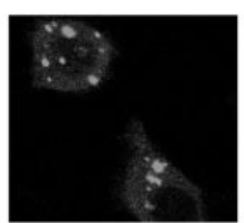

$\operatorname{Cos} 7$

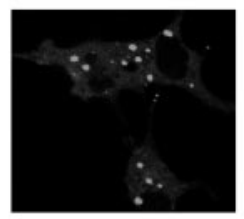

ABP-L
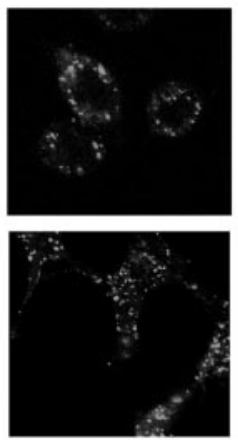
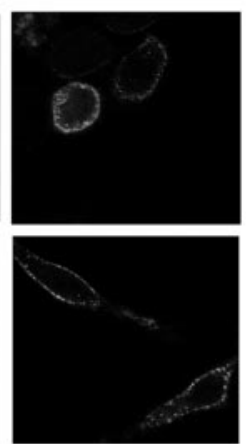

pABP-L
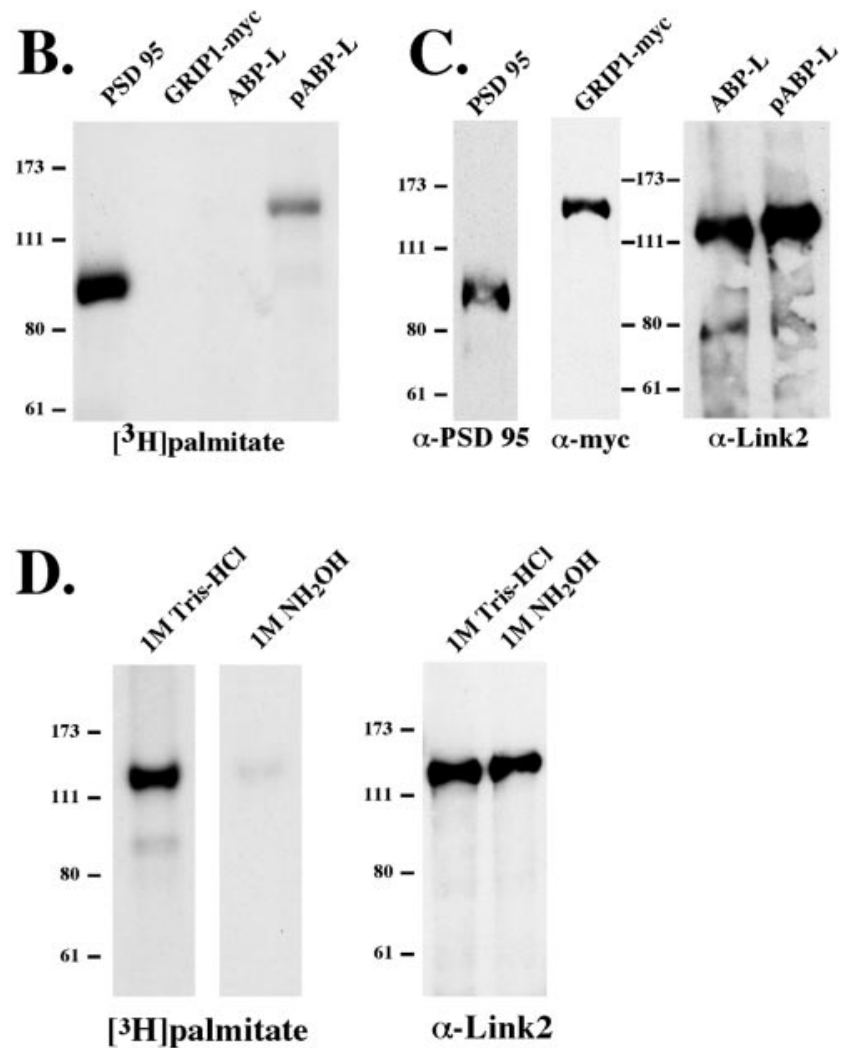

Figure 2. Differential localization and palmitoylation of GRIP1, ABP-L, and pABP-L in heterologous cells. $A$, HeLa cells and COS-7 cells were plated on glass coverslips and transiently transfected with GFP-tagged GRIP and ABP-L cDNAs. Live cells were viewed $24 \mathrm{hr}$ after transfection with a confocal microscope. $B$, COS-7 cells were transiently transfected with PSD95, GRIP1, pABP-L, and ABP-L and metabolically labeled with $\left[{ }^{3} \mathrm{H}\right]$ palmitate. Cells were lysed in RIPA buffer, and the solubilized material was immunoprecipitated with the corresponding antisera. The IP was loaded onto $8 \%$ SDS gels and analyzed by fluorography. $C$, Equal amounts $(1 / 10$ of IP) of samples from $B$ were subjected to SDS-PAGE and Western blotting to check protein expression. $D$, Duplicate plates of COS cells were transfected with pABP-L and metabolically labeled with $\left[{ }^{3} \mathrm{H}\right]$ palmitate. Samples were subjected to $8 \%$ SDS-PAGE, and gel slices were incubated for $24 \mathrm{hr}$ in either $1 \mathrm{M}$ hydroxylamine $\left(\mathrm{NH}_{2} \mathrm{OH}\right)$ or $1 \mathrm{M}$ Tris- $\mathrm{HCl}$ before fluorography. Equal amounts of cell lysate were subjected to Western blot analysis.

which was a positive control (Fig. 2B). GRIP and ABP-L were not palmitoylated, although the expression of both of these proteins in transfected COS cells was high (Fig. 2C). It was surprising that GRIP, which has two cysteine residues within its N-terminal leader at positions 8 and 10, was not palmitoylated in COS cells. However, unlike PSD-95 and pABP-L, the cysteine residues in GRIP are not surrounded by hydrophobic residues and therefore do not conform to the proposed hydrophobic consensus palmitoylation sequence (Dong et al., 1997; El-Husseini et al., 2000b). To determine whether the $\left[{ }^{3} \mathrm{H}\right]$ palmitic acid was linked to pABP-L via a thioester bond to a cysteine residue, which is hydroxylamine sensitive, we treated duplicate gels containing labeled pABP-L with either $1 \mathrm{~m}$ hydroxylamine or $1 \mathrm{~m}$ Tris-HCl buffer for $24 \mathrm{hr}$. Subsequent fluorography of the gels shows that the incorporated $\left[{ }^{3} \mathrm{H}\right]$ palmitate was completely removed by hydroxylamine (Fig. $2 D$ ), confirming thioester linkage. We conclude that pABP-L, but not ABP-L or GRIP (GRIP-1), is palmitoylated.

\section{Palmitoylation of PABP-L on Cys-11 mediates membrane localization}

To determine directly whether the Cys- 11 in PABP-L is the site of palmitoylation, we mutated Cys-11 to an alanine residue (mutant C11A). In addition, we mutated the two hydrophobic leucines surrounding Cys-11 to hydrophilic serine residues (mutant L10,12S) (Fig. 3A) and determined the effect of these mutations on both protein palmitoylation and membrane localization of pABP-L. COS cells transfected with the mutants or WT pABP-L were labeled with $\left[{ }^{3} \mathrm{H}\right]$ palmitic acid and immunoprecipitated using an ABP-specific antibody directed against the linker 2 region of ABP (Srivastava et al., 1998). Western blotting showed that equivalent amounts of the wild-type and mutant pABP-L were isolated from COS cells (Fig. 3C). Fluorography showed that the mutation of the Cys-11 completely abolished palmitoylation. However, mutation of the surrounding amino acids as in the L10,12S mutant had no effect on palmitoylation (Fig. 3B). The subcellular localization of these mutants in COS cells reflected the palmitoylation state. Thus, the nonpalmitoylated C11A mutant formed large clusters that were not associated with the plasma membrane, whereas the palmitoylated wt $\mathrm{pABP}-\mathrm{L}$ protein and the L10,12S mutant were strongly associated with the membrane (Fig. 3D). It was surprising that the L10,12S mutation did not affect either palmitoylation or membrane localization of pABP-L. This is in contrast to the case of PSD-95, for which mutation of the hydrophobic residues surrounding the palmitoylation site blocked palmitoylation (El-Husseini et al., 2000b).

To determine whether amino acids other than Cys-11 in the $\mathrm{N}$ terminus are important for palmitoylation of pABP-L, we individually mutated the first 16 amino acids of pABP-L to alanine residues starting with arginine in position 2 (R2A). These mutant constructs were then transfected into COS cells and assayed for palmitoylation (Fig. 4A). In addition to the Cys-11 mutation, two other mutations unexpectedly blocked palmitoylation: mutation of either the tryptophan in position 4 or the arginine in position 6 to alanines (W4A and R6A). Taking these results into account, Figure $4 B$ shows that membrane localization of pABP-L is strictly dependent on palmitoylation. Mutations that block palmitoylation, W4A and R6A, do not localize at the plasma membrane, whereas the remaining mutants, which are palmitoylated, readily associated with the plasma membrane. The molecular contributions of residues W4 and R6 to palmitoylation of pABP-L are unclear because the protein palmitoyl transferases involved in the palmitoylation of PDZ proteins are not known, and, therefore, their substrate requirements have not yet been determined. However, it appears that the palmitoylation of pABP-L at its single cysteine in the $\mathrm{N}$ terminus relies on hydrophobic and basic 

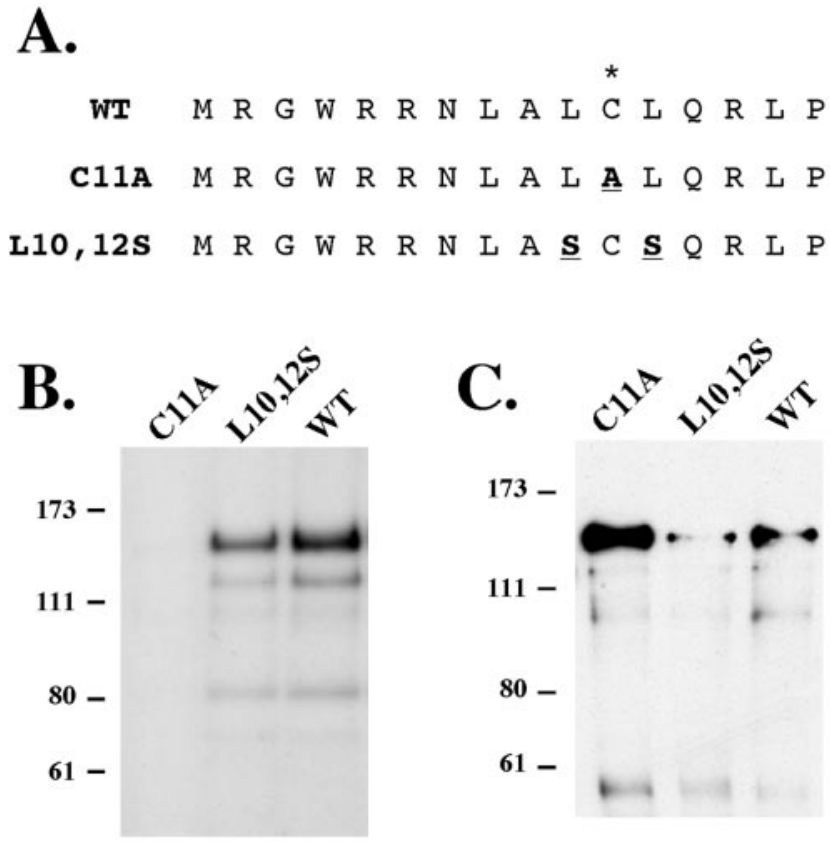

$[3 \mathbf{H}]$ palmitate

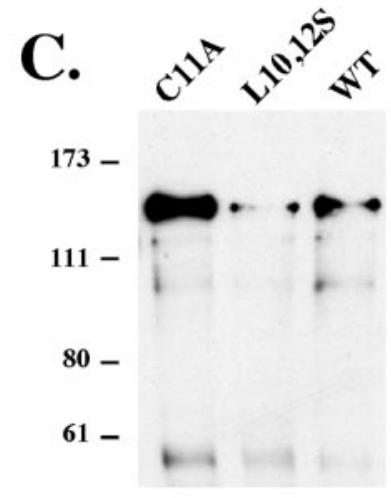

\section{$\alpha$-Link2}
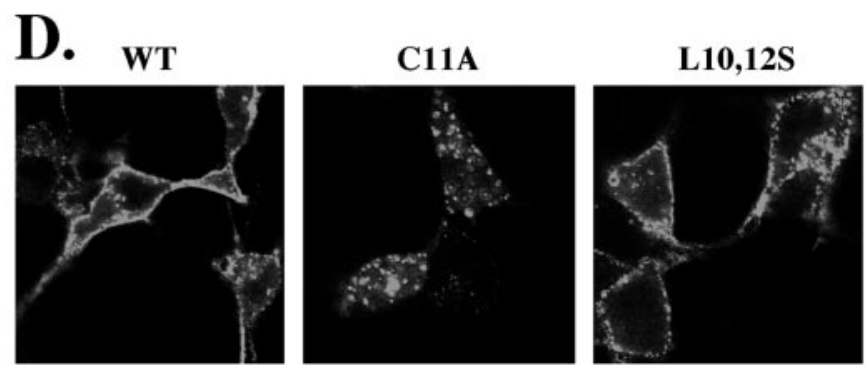

Figure 3. Mutation of Cys-11 abolishes palmitoylation and disrupts membrane localization of pABP-L. $A$, The $\mathrm{N}$ terminus of pABP-L has a cysteine residue in the 11th position (asterisk), which was mutated to an alanine residue (C11A). The two leucines in positions 10 and 12 were also mutated to serine residues (L10,12S). COS cells were transfected with GFP plasmids containing WT pABP-L and C11A and SCS mutants. Cells were metabolically labeled with $\left[{ }^{3} \mathrm{H}\right]$ palmitate, lysed in RIPA buffer, and immunoprecipitated with $1 \mu \mathrm{g}$ of Link2 Ab. Proteins were separated on $8 \%$ SDS-PAGE and subjected to fluorography $(B)$ and Western blotting $(C)$. The localization of the transfected proteins was visualized in live COS cells $24 \mathrm{hr}$ after transfection $(D)$.

amino acids distinct from the PSD-95 consensus sequence for palmitoylation.

\section{Differential colocalization of ABP-L and PABP-L with AMPA receptors in hippocampal neurons}

We showed that ABP-L and pABP-L associate with GluR2 in heterologous cells. To determine whether ABP-L and pABP-L associate with GluR2 in neurons, we coinfected cultured embryonic hippocampal neurons (14-21 d in culture) with Sindbis viruses expressing either GFP-tagged pABP-L or ABP-L together with a virus expressing GluR2 carrying an extracellular Myc epitope tag, MycGluR2 (Osten et al., 2000). At 18-24 hr after infection, monoclonal anti-Myc $\mathrm{Ab}$ was used to detect MycGluR2 on the plasma membrane surface of living neurons. After fixing and permeabilizing the cells, polyclonal anti-Myc Ab was used to detect intracellular pools of MycGluR2. Figure 5 shows the localization of the ABP isoform (green) and surface

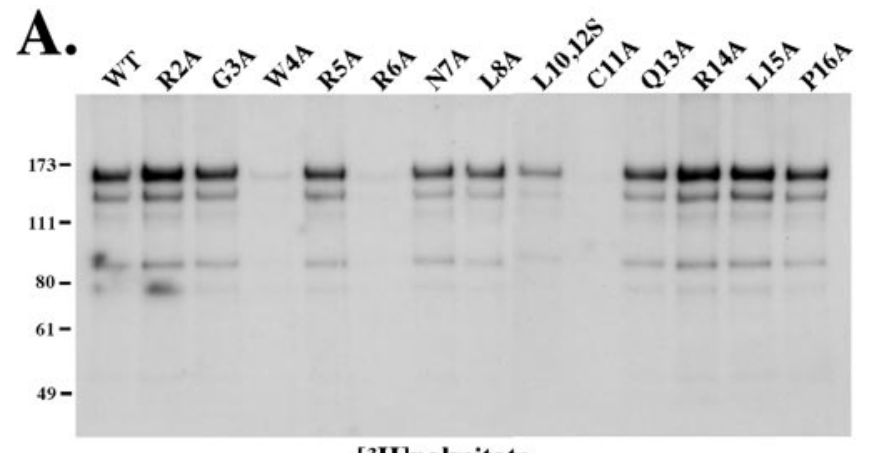

[3H]palmitate

B.
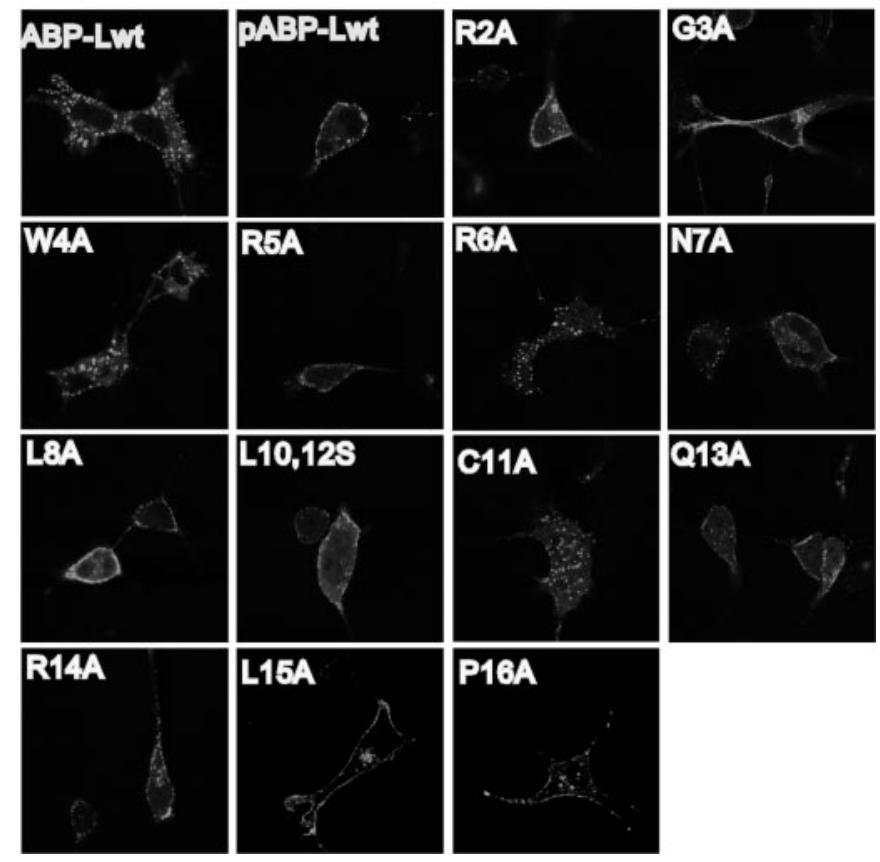

Figure 4. Mutations of the pABP-L N terminus that block palmitoylation have a corresponding effect on membrane localization. $A$, The first 16 amino acids of pABP-L were individually mutated to alanines, except for leucine 10 and 12, which were simultaneously mutated to serines (L10,12S). COS cells were transiently transfected with these mutant pABP-L-GFP plasmids, metabolically labeled with $\left[{ }^{3} \mathrm{H}\right]$ palmitate, lysed in RIPA buffer, and immunoprecipitated with $1 \mu \mathrm{g}$ of Link $2 \mathrm{Ab}$. Proteins were separated on $8 \%$ SDS-PAGE and subjected to fluorography. $B$, The localization of these GFP-tagged mutant proteins was visualized in live COS cells $24 \mathrm{hr}$ after transfection.

and internal MycGluR2 (red and blue, respectively) in representative double-infected neurons. pABP-L forms small puncta that are closely associated with the cell membrane and is found abundantly in spine structures. In contrast, ABP-L is abundant in the cell body and is also found in dendritic shafts in dense, most likely membrane-associated pools but is rarely detected in spines (Fig. 5A). As reported previously (Osten et al., 2000), surface MycGluR2 is readily seen in distinct clusters around the cell body and also along dendritic branches in spine heads (red). Internal pools of MycGluR2 receptors (blue) colocalized very well with ABP-L (green) in both the cell body and along dendritic shafts (Fig. $5 A$, powder blue in the merged image) and is conspicuously absent from spines (Fig. 5B, bottom panels, arrows). In contrast, pABP-L colocalized extensively with surface MycGluR2, especially in morphologically identifiable spines (Fig. 5B, top panels, 


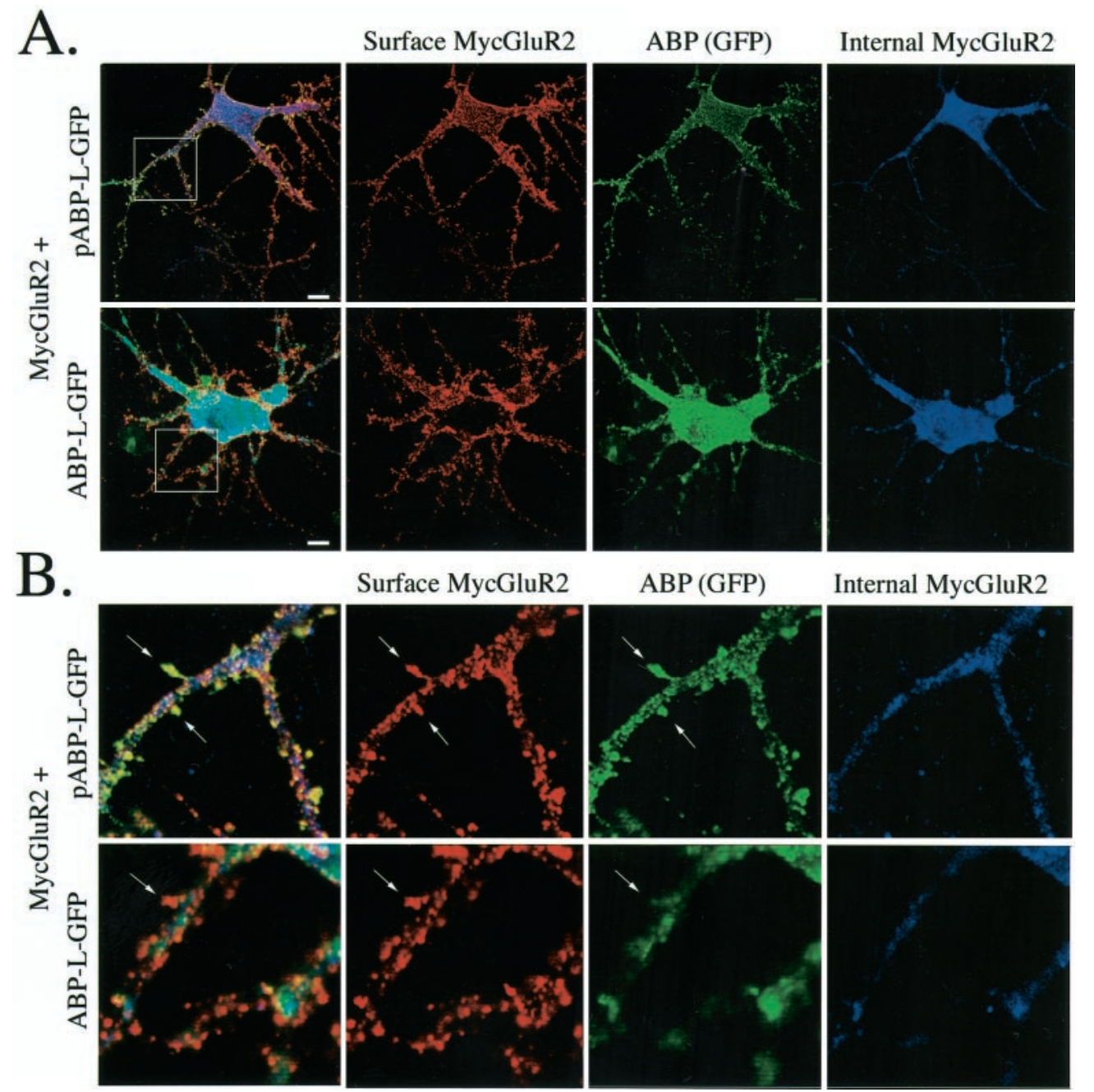

Figure 5. Colocalization of MycGluR2 with $\mathrm{pABP}-\mathrm{L}$ and ABP-L in cultured hippocampal neurons. $A$, Immunostaining of neurons coinfected with Sindbis virus expressing GFP-tagged pABP-L or ABP-L and MycGluR2. At 18-24 hr after infection, living neurons were labeled with monoclonal anti-Myc $\mathrm{Ab}$ to visualize surface GluR2 receptors (red channel). After fixation, neurons were permeabilized and labeled with polyclonal anti-Myc $\mathrm{Ab}$ to visualize internal MycGluR2 receptors (blue channel). Both ABP-L and pABP-L are GFP tagged (green channel). Scale bars, 10 $\mu \mathrm{m}$. $B$, Higher magnification (boxed region shown in $A$ ) showing colocalization of pABP-L with surface MycGluR2 in morphologically distinct spines (arrows, top panels) and the absence of nonpalmitoylated ABP-L in spine structures (arrows, bottom panels). arrows) but not with internal MycGluR2. It therefore appears that these two forms of ABP-L associate with separate and distinct pools of the receptor, such that nonpalmitoylated ABP-L colocalized with internal MycGluR2, whereas palmitoylated pABP-L colocalized with MycGluR2 at the plasma membrane.

To confirm that pABP-L localized in spines, we costained infected neurons with an antibody to GluR1 that readily labels glutamate receptor containing spines in hippocampal pyramidal neurons (Fig. 6A). In addition to wild-type pABP-L, two Flagtagged mutants of pABP-L in which palmitoylation is blocked (Flag-C11A and Flag-W4A) were also used. Flag-pABP-L WT formed puncta that colocalized very well with GluR1 and was found abundantly in spine heads. Overexpressed Flag-C11A also formed puncta that were either absent from spine heads (Fig. 6 $\mathrm{A}$, large arrows in middle panels) or were at a reduced level in spine heads (small arrows, middle panels). In contrast, the Flag-W4A mutant appeared diffuse and formed no distinct puncta, although levels of expression were high in the cell body and in dendritic shafts. However, although the mutant protein was found at the base of the spine, W4A did not localize in spine heads in the majority of synapses observed (Fig. $6 \mathrm{~A}$, right panels). To confirm that, similar to heterologous cells these mutants are also not palmitoylated in neurons, hippocampal cultures infected with these viruses were metabolically labeled for $4 \mathrm{hr}$ with $\left[{ }^{3} \mathrm{H}\right]$ palmitic acid $(1 \mathrm{mCi} / \mathrm{ml}) 24 \mathrm{hr}$ after infection and immunoprecipitated using an ABP-specific linker 2 antibody. Western blotting showed that equivalent amounts of the wild-type and mutant C11A and W4A proteins were isolated from hippocampal cultures (Fig. 6B, right panel). Fluorography showed that wild-type pABP-L was robustly palmitoylated in neurons, whereas both C11A and W4A mutation blocked palmitoylation (Fig. 6B, left panel). It therefore appears that palmitoylation may enhance stabilization of pABP-L at the synapse, because loss of palmitoylation (C11A and W4A) results in reduced accumulation of $\mathrm{ABP}$ in spines.

In contrast to pABP-L, virally expressed GRIP in neurons appears as large dense intracellular clusters that are mainly in the cell body and proximal dendrites (Fig. $7 A$, right panel ). To determine whether the N-terminal palmitoylation signal of pABP-L is capable of targeting GRIP1 to spines and synaptic membranes, we replaced the $\mathrm{N}$ terminus of GRIP1 with the 52 aa $\mathrm{N}$ terminus of pABP-L. The resulting pABP-L(N)/GRIP chimera, when expressed in hippocampal neurons, exhibited a dramatic relocalization compared with native GRIP protein. The chimera was now found in small puncta located abundantly in spines, a distribution very similar to that seen with pABP-L (Fig. $7 A$ ). In two separate experiments, we counted the number of cells that expressed different exogenous PDZ proteins in spines. Figure $7 B$ shows that $100 \%$ of the neurons expressing pABP-L localized the protein in spines (40 of 40). In contrast, only $\sim 30 \%$ of neurons infected with the GRIP virus localized the protein in morphologically distinct 
A.

Figure 6. Palmitoylation of pABP-L is critical for localization into spines. $A$, Immunostaining of neurons infected with Sindbis virus expressing Flag-tagged pABP-L, C11A, or W4A proteins. At 18-24 hr after infection, fixed neurons were labeled with a polyclonal GluR1 C-terminal antibody to visualize endogenous GluR1 receptors and a monoclonal anti-Flag antibody to visualize virally expressed ABP proteins. Higher magnification (boxed region) showing colocalization of pABP-L ( green) with GluR1 (red) in morphologically distinct spines (filled arrows, left panels). Reduced levels of the nonpalmitoylated C11A mutant protein (open arrows, middle panel) and the absence of mutant protein (filled arrows, middle panel) in GluR1 containing spines were also observed. In contrast, the W4A mutant protein was diffuse rather than punctate and was absent from spine heads ( filled arrows, right pan$e l s)$. $B$, Hippocampal cultures were infected with the same viruses used in $A$ and metabolically labeled with $\left[{ }^{3} \mathrm{H}\right]$ palmitate. Cells were lysed, and solubilized material was immunoprecipitated with $1 \mu \mathrm{g}$ of Link2 Ab. The IP was loaded onto $8 \%$ SDS gels and analyzed by fluorography (left panel) and shows that only WT pABP-L is palmitoylated, whereas both C11A and W4A mutant proteins are not palmitoylated in neurons. Equal amounts ( $1 / 10$ of IP) of each sample were subjected to SDS-PAGE and Western blotting to check protein expression (right panel).

spines (13 of 40). The pABP-L $\mathrm{N}$ terminus was capable of redirecting a significant proportion $(\sim 80 \%)$ of the chimeric GRIP protein to spines (33 of 40). It therefore appears that the $\mathrm{N}$ terminus of pABP-L can override the intracellular localization of GRIP protein and target it to spines. Recently, a palmitoylated form of mouse GRIP (GRIP1) called GRIP1b was reported (Yamazaki et al., 2001). This isoform has an N-terminal sequence very similar to the palmitoylated region of pABP-L (Fig. 7C).

\section{DISCUSSION}

Here we report the cloning and characterization of pABP-L, a novel N-terminal variant of rat ABP-L, which is a seven PDZ domain-containing protein that interacts with AMPA receptors (Dong et al., 1997; Srivastava et al., 1998; Bruckner et al., 1999; Dong et al., 1999b; Braithwaite et al., 2000). pABP-L is palmitoylated within a unique 18 aa $\mathrm{N}$-terminal sequence generated by alternative splicing. Palmitoylation targets pABP-L to the plasma membrane in heterologous cells, whereas in neurons it targets pABP-L to spines. The nonpalmitoylated ABP-L, in contrast, is confined to intracellular clusters most likely consisting of intracellular membrane structures. The distribution of GRIP, which lacks palmitate, resembles that of ABP-L and is also confined to intracellular membrane structures. However, the pABP-L(N)/ GRIP chimera is targeted to spines. This suggests that GRIP
C11A
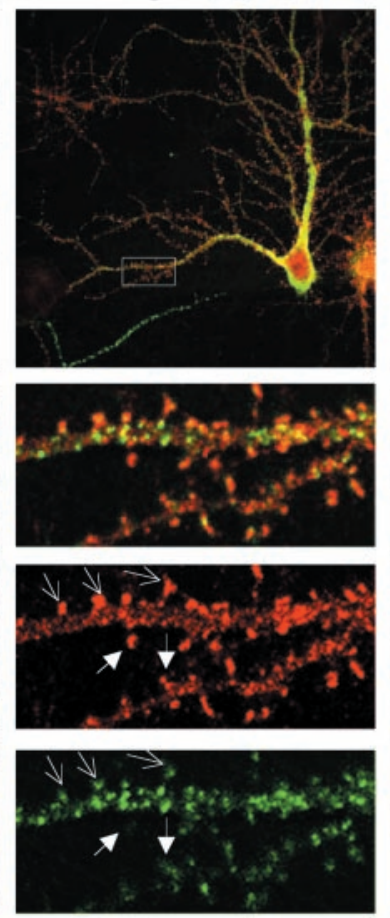

W4A
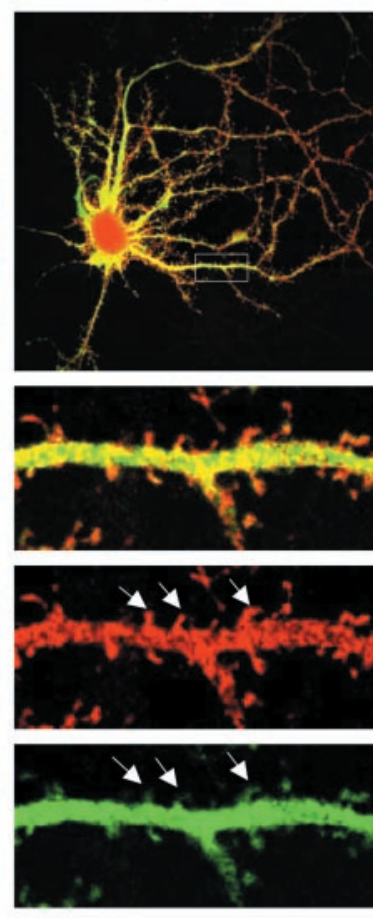

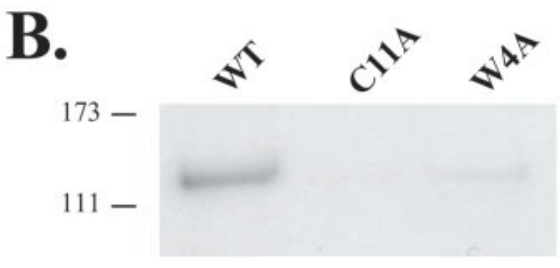

$\left[{ }^{3} \mathrm{H}\right]$ palmitate

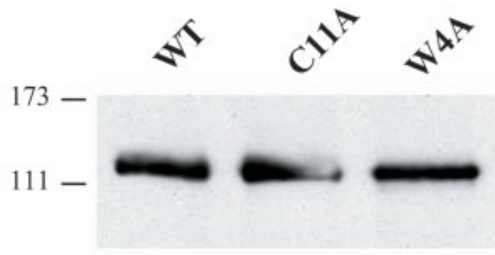

$\alpha$-Link2 bearing an N-terminal palmitate would be targeted similarly to pABP-L. Recently, a mouse GRIP N-terminal isoform, GRIP1b, has been reported that is also palmitoylated on a cysteine at position 11 (Yamazaki et al., 2001). Thus, our work suggests that GRIP1b will also be spine targeted. We showed that GRIP and ABP, although encoded by different genes, are both expressed in palmitoylated and nonpalmitoylated forms, as is PSD-95, which binds the NMDA receptor. The expression of glutamate receptor binding proteins as palmitoylated and nonpalmitoylated pairs implies functions for both forms.

Many ion channels and their associated intracellular signaling proteins interact at synapses with PDZ-containing proteins. The most well understood example of this is the NMDA receptor/ PSD-95 interaction that provides a scaffold for the association of peptides that function in several signal transduction cascades (for review, see Sheng and Pak, 2000). Synaptic targeting of PSD-95 is dependent on lipid modification of two cysteine residues at the $\mathrm{N}$ terminus through the addition of palmitate. Mutations of PSD-95 that abolish palmitoylation reduced the synaptic targeting of PSD-95 and its ability to interact with the ion channel $\mathrm{K}_{\mathrm{v}} 1.4$ (Topinka and Bredt, 1998; Craven et al., 1999; El-Husseini et al., $2000 \mathrm{~b}$ ). We showed that palmitoylation of pABP-L is essential for membrane localization and that the $\mathrm{N}$ terminus of pABP-L is 


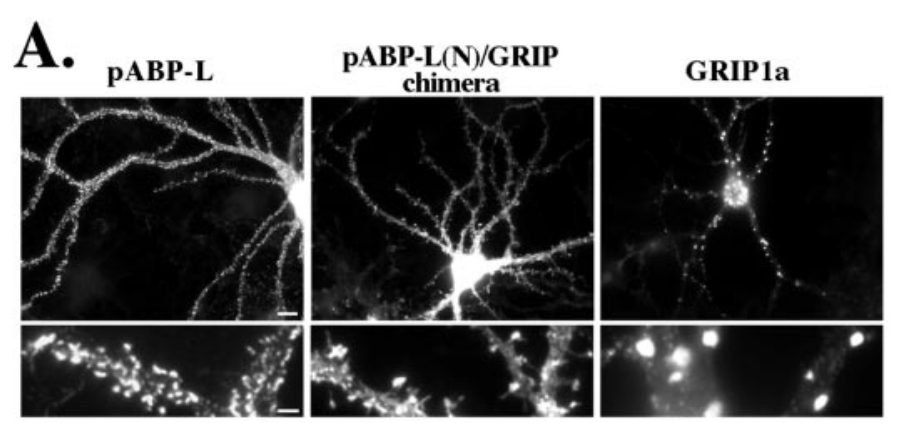

B.

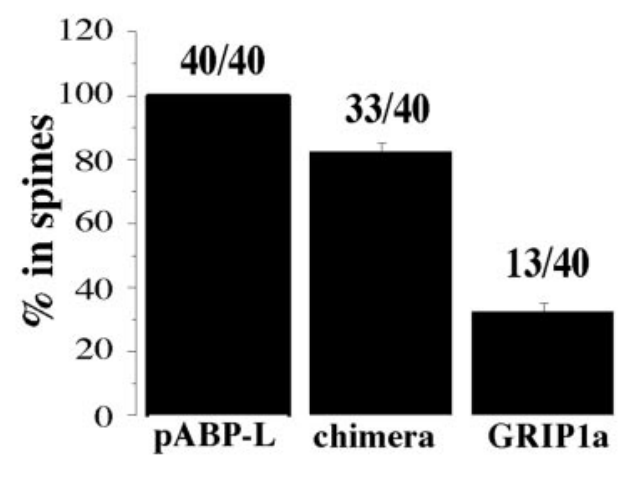

Non-palmitoylated:

ABP-L M L A V S L K W R L G V V R R R P K GRIP1a M I A V S F K C R C Q I L R R L T K

\section{Palmitoylated:}

\section{pABP-L M R G W R R N L A L C L Q R L P D E GRIP1b M P G W K K N I P I c L Q A E E Q E}

Figure 7. The $\mathrm{N}$ terminus of $\mathrm{pABP}-\mathrm{L}$ is responsible for synaptic targeting. $A$, Immunostaining of hippocampal neurons infected with Sindbis virus expressing pABP-L-Flag, GRIP1-Myc, or a fusion pABP-L(N)/ GRIP1-Myc protein (chimera). Exogenous proteins were detected with either the Myc or Flag antibody. pABP-L is found mainly in spines, whereas GRIP1 is mainly in large dense macroclusters in the cell body and dendritic shafts. The chimeric protein containing the first 52 aa of pABP-L is sufficient to target the rest of the GRIP1 protein to spines. Scale bars: top panels, $10 \mu \mathrm{m}$; bottom panels, $2.5 \mu \mathrm{m}$. B, Bar graph showing percentage of cells that expressed the exogenous protein in spines. The total number of cells counted from two separate experiments is indicated. $C$, Schematic showing comparison of palmitoylated and nonpalmitoylated ABP-L and GRIP1 N-terminal sequences. Note that both proteins have a cysteine residue at position 11 that is palmitoylated (bold and underlined) and have hydrophobic and charged residues at positions 4 and 6, respectively (bold).

sufficient to target GRIP to spines. The sequences surrounding the cysteine residue in PABP-L are similar to those found in PSD-95, in that hydrophobic residues flank the palmitoylated cysteines in both proteins. Mutations of these hydrophobic residues in PSD-95 also abolish palmitoylation and suggest a consensus palmitoylation sequence for PDZ proteins (El-Husseini et al., $2000 \mathrm{~b}$ ). However, mutation of the neighboring hydrophobic residues in the pABP-L $\mathrm{N}$ terminus did not affect palmitoylation, indicating that pABP-L does not conform to the PSD-95 consensus sequence. Unexpectedly, mutations of tryptophan 4 and arginine 6 of pABP-L disrupted palmitoylation. The hydrophobic $(\mathrm{W})$ and basic $(\mathrm{R})$ residues identified here as necessary for pal- mitoylation may increase overall hydrophobicity and positive charge of the $\mathrm{N}$ terminus, strengthening its interaction with phospholipid membranes and caveolae (van't Hof and Resh, 2000), leading to palmitoylation (for review, see Resh, 1999). Interestingly, the $\mathrm{N}$ terminus of the recently cloned mouse GRIP1b, which is palmitoylated on a single cysteine at position 11, also has a hydrophobic tryptophan (W) residue at position 4 and a basic lysine (K) residue at position 6 (Fig. 6C) (Yamazaki et al., 2001). These basic and hydrophobic residues may therefore have a similar function in the palmitoylation of both GRIP1b and pABP-L.

The role of palmitoylation in the "targeting" of proteins to the plasma membrane is debatable because the enzyme that catalyzes the reaction, palmitoyl acyl transferase, is enriched in the plasma membrane itself (Dunphy et al., 1996). Palmitoylated proteins often have other lipophilic or charged groups (such as myristate, farnesyl, or clusters of basic hydrophobic residues) that readily associate with the plasma membrane (for review, see Resh, 1999). However, it is thought that palmitoylation stabilizes proteins at the plasma membrane by partitioning proteins into special lipid microdomains or rafts (Shahinian and Silvius, 1995). Our observations in neurons suggest that the hydrophobic and basic residues of pABP-L (and likely GRIP1b as well) are involved in initially bringing the molecule to the plasma membrane and spines. The W4A mutant, which still has an intact cysteine, is not palmitoylated and is found in a diffuse, nonpunctate pattern in the cytoplasm, and does not appear to be associated with any membrane bound organelle, either intracellularly or with the plasma membrane (Fig. 6). The C11A mutant, which still has intact lipophilic residues, maintains a punctate pattern of expression and can occasionally be found in spines, although at a reduced level. This suggests that, although the C11A mutant protein can reach the synapse, in the absence of the cysteine residue the protein is not palmitoylated and therefore is not stabilized at this location. In addition, C11A molecules that reach the plasma membrane may dimerize with endogenous ABP or GRIP proteins (Srivastava et al., 1998). This could also account

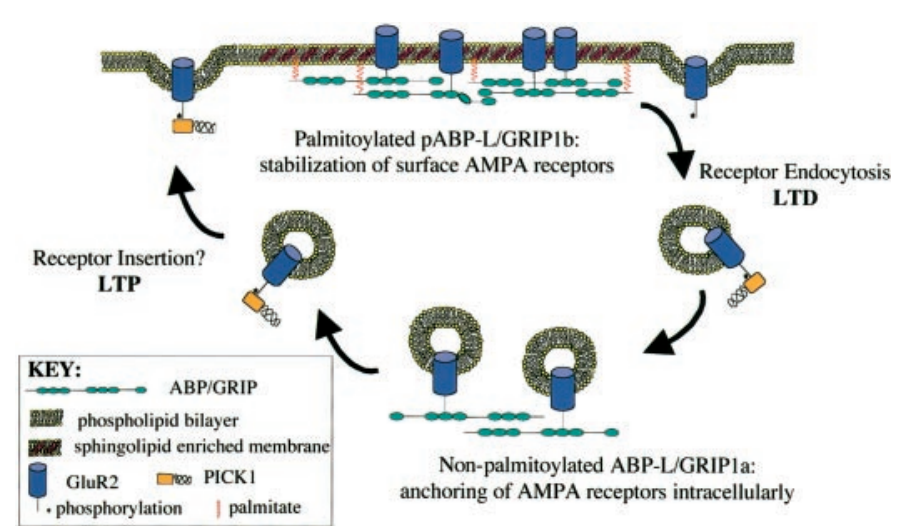

Figure 8. Schematic showing a model of the anchoring function of ABP-L splice variants. During the process of LTP and LTD, AMPA receptors rapidly cycle between membrane and intracellular locations either via receptor endocytosis or receptor insertion. The two identified splice variants of ABP-L/GRIP provide a scaffold for the anchorage of GluR2 containing AMPA receptors at both intracellular and synaptic locations. Membrane-targeted palmitoylated pABP-L/GRIP1b stabilizes AMPA receptors at the synaptic membrane, whereas nonpalmitoylated intracellular ABP-L/GRIP1a anchors AMPA receptors at extrasynaptic, intracellular locations. 
for the continued presence of the mutant C11A protein at synapses that we observe.

The energetics of binding of proteins to lipid membranes by fatty acids suggest that two fatty acid modifications may be required for stable membrane association (Shahinian and Silvius, 1995; van't Hof and Resh, 2000). This requirement may also be satisfied by the interaction of two proteins that each undergo lipid modification and exert additive effects on membrane association. pABP-L contains only a single palmitoylation site, at Cys-11. However, ABP is able to multimerize (Srivastava et al., 1998; Dong et al., 1999b), thereby potentially strengthening its membrane attachment. In addition, palmitoylation may be a signal for segregation of receptors and their associated proteins into detergent-resistant, glycosphingolipid-enriched raft-like microdomains of the plasma membrane. Raft localization and/or targeting of proteins can result in an increase in local protein concentrations, which facilitates protein-protein interactions. It is thought that these membrane rafts could therefore serve as a platform for organizing and assembling macromolecular signaling complexes. In this connection, it is noteworthy that complexes of GRIP/ABP with ephrins are recruited into sphingolipid- and cholesterol-rich raft microdomains (Bruckner et al., 1999).

We showed that ABP-L and pABP-L are targeted to different subcellular locations in neurons. ABP-L accumulated mainly in the cell body and dendritic shafts and is conspicuously absent from spine-like structures. pABP-L in contrast is targeted to the cell membrane and is found abundantly in spines. In addition, these two ABP proteins colocalize with separate and distinct pools of AMPA receptors, in which the nonpalmitoylated ABP-L protein colocalizes with internal GluR2 receptors, whereas the palmitoylated, plasma membrane-associated pABP-L colocalizes extensively with GluR2 receptors at the synaptic membrane. Although ABP and GRIP expression in rat brain neurons overlap, a large proportion of neurons examined strongly expressed one protein while weakly expressing the other (Burette et al., 2001). In addition, although all proximal dendrites and the soma contained both proteins, $60 \%$ of distal GluR2-containing synapses were positive for either ABP or GRIP alone, whereas $40 \%$ had both. This suggests that these proteins may act either in concert with or independently from each other at individual synapses in providing a molecular scaffold for AMPA receptor anchorage. Although our data show that the two forms of ABP may provide two separate AMPA receptor anchorages at ABPonly synapses, the recent identification of palmitoylated GRIP1b also provides for both membrane and intracellular AMPA receptor anchors at GRIP-only synapses.

It is clear that, during some forms of LTP and LTD, AMPA receptors are shuttled between intracellular and membrane locations. For example, during LTP and the activation of silent synapses, AMPA receptors are rapidly inserted and stabilized at active synapses, thereby increasing the number of functional AMPA receptors at the synapse and the strength of the response (Shi et al., 1999; Lu et al., 2001). Conversely, during LTD, PKC phosphorylation at serine 880 within the $\mathrm{C}$ terminus of GluR2 at the membrane leads to rapid internalization of the receptor, because the anchoring proteins ABP/GRIP are unable to bind to the phosphorylated receptor (Chung et al., 2000; Matsuda et al., 2000; Perez et al., 2001; Xia et al., 2001). After dephosphorylation, internalized receptors can potentially reassociate with internal membrane pools of ABP/GRIP, preventing the transport of AMPA receptors back to the synaptic membrane for the maintenance of LTD (Daw et al., 2000). The phosphorylated form of
GluR2 interacts with PKC-interacting protein (PICK1), and the resulting GluR2/PICK1 complex is thought to shuttle from intracellular to plasma membrane locations or vice versa. Unlike PICK1, ABP and GRIP would serve to stabilize and anchor the receptors both at synaptic and intracellular membranes. Our observations of intracellular and synaptic membrane-associated forms of ABP and GRIP are consistent with this model (Fig. 8). The identification of two forms of ABP that reside at different subcellular locations suggests that they serve two different purposes. Intracellular, nonpalmitoylated ABP/GRIP1a is associated with intracellular GluR2 and may retain GluR2 at subcellular locations, preventing interaction with PICK1 and the formation of the mobile GluR2/PICK1 complex. In contrast, synaptic membrane-associated, palmitoylated pABP-L, and possibly GRIP1b, may stabilize surface AMPA receptors, potentially targeting them to caveolae and rafts, thus providing a platform for the assembly and interaction with other proteins and the formation of signaling complexes.

\section{REFERENCES}

Alland L, Peseckis SM, Atherton RE, Berthiaume L, Resh MD (1994) Dual myristoylation and palmitoylation of Src family member p59fyn affects subcellular localization. J Biol Chem 269:16701-16705.

Braithwaite SP, Meyer G, Henley JM (2000) Interactions between AMPA receptors and intracellular proteins. Neuropharmacology 39:919-930.

Brakeman PR, Lanahan AA, O'Brien R, Roche K, Barnes CA, Huganir RL, Worley PF (1997) Homer: a protein that selectively binds metabotropic glutamate receptors. Nature 386:284-288.

Bruckner K, Pablo Labrador J, Scheiffele P, Herb A, Seeburg PH, Klein R (1999) EphrinB ligands recruit GRIP family PDZ adaptor proteins into raft membrane microdomains. Neuron 22:511-524.

Burette A, Khatri L, Wyszynski M, Sheng M, Ziff E, Weinberg R (2001) Differential cellular and subcellular localization of AMPA receptorbinding protein and glutamate receptor-interacting protein. J Neurosci 21:495-503.

Carroll RC, Lissin DV, von Zastrow M, Nicoll RA, Malenka RC (1999) Rapid redistribution of glutamate receptors contributes to long-term depression in hippocampal cultures. Nat Neurosci 2:454-460.

Chomczynski P, Sacchi N (1987) Single-step method of RNA isolation by acid guanidinium thiocyanate-phenol-chloroform extraction. Anal Biochem 162:156-159.

Chung HJ, Xia J, Scannevin RH, Zhang X, Huganir RL (2000) Phosphorylation of the AMPA receptor subunit GluR2 differentially regulates its interaction with PDZ domain-containing proteins. J Neurosci 20:7258-7267.

Craven SE, El-Husseini AE, Bredt DS (1999) Synaptic targeting of the postsynaptic density protein PSD-95 mediated by lipid and protein motifs. Neuron 22:497-509.

Daw MI, Chittajallu R, Bortolotto ZA, Dev KK, Duprat F, Henley JM, Collingridge GL, Isaac JT (2000) PDZ proteins interacting with C-terminal GluR2/3 are involved in a PKC-dependent regulation of AMPA receptors at hippocampal synapses. Neuron 28:873-886.

Dong H, O’Brien RJ, Fung ET, Lanahan AA, Worley PF, Huganir RL (1997) GRIP: a synaptic PDZ domain-containing protein that interacts with AMPA receptors. Nature 386:279-284.

Dong H, Zhang P, Liao D, Huganir RL (1999a) Characterization, expression, and distribution of GRIP protein. Ann NY Acad Sci 868:535-540.

Dong H, Zhang P, Song I, Petralia RS, Liao D, Huganir RL (1999b) Characterization of the glutamate receptor-interacting proteins GRIP1 and GRIP2. J Neurosci 19:6930-6941.

Dunphy JT, Greentree WK, Manahan CL, Linder ME (1996) G-protein palmitoyltransferase activity is enriched in plasma membranes. J Biol Chem 271:7154-7159.

El-Husseini AE, Topinka JR, Lehrer-Graiwer JE, Firestein BL, Craven SE, Aoki C, Bredt DS (2000a) Ion channel clustering by membraneassociated guanylate kinases. Differential regulation by $\mathrm{N}$-terminal lipid and metal binding motifs. J Biol Chem 275:23904-23910.

El-Husseini AE, Craven SE, Chetkovich DM, Firestein BL, Schnell E, Aoki C, Bredt DS (2000b) Dual palmitoylation of PSD-95 mediates its vesiculotubular sorting, postsynaptic targeting, and ion channel clustering. J Cell Biol 148:159-172.

Hancock JF, Magee AI, Childs JE, Marshall CJ (1989) All ras proteins are polyisoprenylated but only some are palmitoylated. Cell 57:1167-1177.

Hayashi Y, Shi SH, Esteban JA, Piccini A, Poncer JC, Malinow R (2000) 
Driving AMPA receptors into synapses by LTP and CaMKII: requirement for GluR1 and PDZ domain interaction. Science 287:2262-2267.

Hollmann M, Heinemann S (1994) Cloned glutamate receptors. Annu Rev Neurosci 17:31-108.

Kornau HC, Schenker LT, Kennedy MB, Seeburg PH (1995) Domain interaction between NMDA receptor subunits and the postsynaptic density protein PSD-95. Science 269:1737-1740.

Leonard AS, Davare MA, Horne MC, Garner CC, Hell JW (1998) SAP97 is associated with the alpha-amino-3-hydroxy-5-methylisoxazole4-propionic acid receptor GluR1 subunit. J Biol Chem 273:19518-19524.

Lu W, Man H, Ju W, Trimble WS, MacDonald JF, Wang YT (2001) Activation of synaptic NMDA receptors induces membrane insertion of new AMPA receptors and LTP in cultured hippocampal neurons. Neuron 29:243-254.

Luscher C, Xia H, Beattie EC, Carroll RC, von Zastrow M, Malenka RC, Nicoll RA (1999) Role of AMPA receptor cycling in synaptic transmission and plasticity. Neuron 24:649-658.

Matsuda S, Launey T, Mikawa S, Hirai H (2000) Disruption of AMPA receptor GluR2 clusters following long-term depression induction in cerebellar Purkinje neurons. EMBO J 19:2765-2774.

Mumby SM (1997) Reversible palmitoylation of signaling proteins. Curr Opin Cell Biol 9:148-154.

Niethammer M, Kim E, Sheng M (1996) Interaction between the C terminus of NMDA receptor subunits and multiple members of the PSD-95 family of membrane-associated guanylate kinases. J Neurosci 16:2157-2163.

Osten P, Khatri L, Perez JL, Kohr G, Giese G, Daly C, Schulz TW, Wensky A, Lee LM, Ziff EB (2000) Mutagenesis reveals a role for ABP/GRIP binding to GluR2 in synaptic surface accumulation of the AMPA receptor. Neuron 27:313-325.

Perez J, Khatri L, Chang S, Srivastava S, Osten P, Ziff EB. (2001) PICK1 targets activated protein kinase $\mathrm{C}$ alpha to AMPA receptor clusters in spines of hippocampal neurons and reduces surface levels of the AMPA-type glutamate receptor subunit 2. J Neurosci 21:5417-5428.

Resh MD (1996) Regulation of cellular signalling by fatty acid acylation and prenylation of signal transduction proteins. Cell Signal 8:403-412.

Resh MD (1999) Fatty acylation of proteins: new insights into membrane targeting of myristoylated and palmitoylated proteins. Biochim Biophys Acta 1451:1-16.
Shahinian S, Silvius JR (1995) Doubly-lipid-modified protein sequence motifs exhibit long-lived anchorage to lipid bilayer membranes. Biochemistry 34:3813-3822.

Sheng M, Pak DT (2000) Ligand-gated ion channel interactions with cytoskeletal and signaling proteins. Annu Rev Physiol 62:755-778.

Shi SH, Hayashi Y, Petralia RS, Zaman SH, Wenthold RJ, Svoboda K, Malinow R (1999) Rapid spine delivery and redistribution of AMPA receptors after synaptic NMDA receptor activation. Science 284:1811-1816.

Srivastava S, Osten P, Vilim FS, Khatri L, Inman G, States B, Daly C, DeSouza S, Abagyan R, Valtschanoff JG, Weinberg RJ, Ziff EB (1998) Novel anchorage of GluR2/3 to the postsynaptic density by the AMPA receptor-binding protein ABP. Neuron 21:581-591.

Tomita S, Nicoll RA, Bredt DS (2001) PDZ protein interactions regulating glutamate receptor function and plasticity. J Cell Biol 153:F19-F24.

Topinka JR, Bredt DS (1998) N-terminal palmitoylation of PSD-95 regulates association with cell membranes and interaction with $\mathrm{K}^{+}$channel Kv1. 4. Neuron 20:125-134.

van't Hof W, Resh MD (2000) Targeting proteins to plasma membrane and membrane microdomains by N-terminal myristoylation and palmitoylation. Methods Enzymol 327:317-330.

Wedegaertner PB, Chu DH, Wilson PT, Levis MJ, Bourne HR (1993) Palmitoylation is required for signaling functions and membrane attachment of Gq alpha and Gs alpha. J Biol Chem 268:25001-25008.

Wyszynski M, Kim E, Yang FC, Sheng M (1998) Biochemical and immunocytochemical characterization of GRIP, a putative AMPA receptor anchoring protein, in rat brain. Neuropharmacology 37:1335-1344.

Xia J, Zhang X, Staudinger J, Huganir RL (1999) Clustering of AMPA receptors by the synaptic PDZ domain-containing protein PICK1. Neuron 22:179-187.

Xia J, Chung HJ, Wihler C, Huganir RL, Linden DJ (2001) Cerebellar long-term depression requires PKC-regulated interactions between GluR2/3 and PDZ domain-containing proteins. Neuron 28:499-510.

Yamazaki M, Fukaya M, Abe M, Ikeno K, Kakizaki T, Watanabe M, Sakimura K (2001) Differential palmitoylation of two mouse glutamate receptor interacting protein 1 forms with different $\mathrm{N}$-terminal sequences. Neurosci Lett 304:81-84. 